\title{
"Mudando a história com palavras e persistência” (depoimento e poemas)
}

Navegar pelas histórias, relatadas tanto em poemas e contos nestes quarenta e dois anos de Cadernos Negros, é entrar em contato com a face ocultada de um Brasil que se quis e se quer branco, não só na aparência, na concentração de riqueza que significa poder, mas na possibilidade de sonhar construir um mundo cognitivo onde cabe a beleza de ser. São quarenta e dois anos de construção de uma literatura negra brasileira, a partir do ponto de vista dos silenciados. A referência como ponto de continuação de uma prática que remonta ao século XIX, ${ }^{1}$ no mínimo, é o ano de 1978 quando o Brasil vivenciava o regime ditatorial civil militar, iniciado em 1964, que dava mostra de saturação.

Nessa fase, uma efervescência popular político cultural, não só no eixo Sul Sudeste, questionava-se o racismo sutil e mortífero existente na estrutura social do país, mas negado através de construções científicas falaciosas que alimentavam a ideia de uma democracia racial, tendo o Brasil como paraíso das raças, em contraposição aos confrontos raciais de outros países, que não resolveram as contradições geradas pelo regime mundial escravocrata, que contribuiu para subalternizar e desumanizar os escravizados e seus descendentes. No entanto, o Brasil também não havia resolvido e manteve os cidadãos negros numa situação de exclusão, até hoje, negando por diversos mecanismos, formais e informais, o acesso pleno aos bens sócio-cultural-econômicos oriundos do acúmulo de riquezas através do regime escravocrata.

Em São Paulo, nas reuniões realizadas no CECAN, ${ }^{2}$ Centro de Cultura e Arte Negra, uma associação de ativismo negro brasileiro, fundada em 1971, com um intuito cultural educacional, em 1976, passou a organizar atividades de pesquisas, seminários e conferências sobre assuntos afro-brasileiros, promovendo o desenvolvimento de projetos artísticos, cívicos, culturais, sociais e esportivos, estabelecendo parcerias e contatos com outros grupos do Brasil e do exterior, além de produzir bibliografias, alicerçando ideias para que, em 1978, eclodissem duas importantes ações coletivas. Uma delas o Movimento Negro Unificado, com a reunião de várias entidades negras e com carta convocatória ${ }^{3}$ à população, culminando com o emblemático ato, em 1978, nas escadarias do Teatro Municipal de São Paulo. ${ }^{4}$ Constavam na pauta das reivindicações, as cotas raciais nas universidades, a inclusão nos currículos escolares do ensino da história do continente africano, entre outros assuntos urgentes. 
Outro ponto importante foi o surgimento da coletânea literária Cadernos Negros, iniciativa surgida dentro do CECAN através de debates, tendo como principais articuladores Cuti (codinome de Luiz Silva) e Hugo Ferreira. O volume inaugural foi publicado com poemas de seis autores e duas autoras, com lançamentos no mesmo ano de 1978, o primeiro na cidade de Araraquara, SP, no Festival Comunitário Negro Zumbi, Feconezu, 5 com a presença de mais de duas mil pessoas negras oriundas de várias cidades de São Paulo e de outros estados. ${ }^{6}$ O segundo lançamento, ao molde tradicional, realizou-se na famosa Livraria Teixeira, situada no centro velho de São Paulo, contanto com a presença do sociólogo Florestan Fernandes entre as cinquentas pessoas que compareceram. ${ }^{7} \mathrm{~A}$ disparidade de local e público, entre os dois lançamentos, já apontava o rumo que essa iniciativa literária seguiria nas quatro décadas subsequente.

Cadernos Negros atraiu escritores-escritoras que vinham de experiências de publicações anteriores, alguns provenientes da chamada geração mimeógrafo, muitos também integravam o MNU, além de escritores-escritoras aspirantes em publicar seus textos pela primeira vez. No princípio a maioria do eixo Sul-Sudeste, em edições subsequentes foi agregando escritores-escritoras de outros estados do Brasil. A publicação conquistou também um público leitor sequioso, evidenciando que havia um anseio latente num seguimento da população negra em se ver referenciada de forma positiva nas páginas de um livro. Fora isso, Cadernos Negros despertou nos autores-autoras o interesse em refletir sobre o ofício e a arte da escrita, sobre o que significava ser escritor-escritora negro-negra num contexto social de exclusão explícito e implícito na sociedade brasileira, oriunda do regime das oligarquias escravocratas, cuja produção literária, em maior ou menor medida, refletia e reflete nos textos ficcionais uma visão reducionista, estereotipada e racista do cidadão-cidadã negro-negra brasileiro-brasileira. ${ }^{8}$

Quarenta e dois anos transcorridos, ao refletir sobre essa história, reconheço a lição ancestral que alerta "nossos passos vem de longe", para além de mera frase de efeito ou de ordem, ou ainda de mero fenômeno sazonal de uma época, mas como um diferencial significativo importante, apontando para uma mudança do pensamento intelectual literário brasileiro, a partir das atitudes de escritores-escritoras negros-negras. Posso afirmar, sem sombra de dúvida, que se instaura, a partir daí, o que em minhas palestras denomino de Movimento de Literatura Negra Brasileira, tendo como importante contribuição a realização de encontros informais e formais para refletir sobre o fazer literário, e a publicação dessas discussões, ${ }^{9}$ juntamente com ações de publicações periódicas coletivas e individuais, utilizando recursos para além da formalidade institucional e para enfrentar o que chamamos na época de bloqueio cultural e editorial.

Em suma, o Movimento de Literatura Negra Brasileira trouxe para o cenário cultural das artes literárias os protagonismos diversos das vivências dos-das cidadãos-cidadãs negros-negras brasileiros-brasileiras, relegadas a um porão simbólico da nação, não só em seus aspectos factuais estatísticos, que em última análise são estáticos, mas enfatizando os aspectos cognitivos que envolvem sentimentos, ou seja, uma carga emocional 
que é apreendida ficcionalmente no ofício de escrever literatura. Nesse sentido, passamos a ser sujeito das nossas próprias histórias, desconstruindo e reconstruindo a história da nação, a partir do momento que deixamos, simplesmente, de ser mero objeto das histórias alheias, que traduzem pontos de vistas herdados na formação de brasilidade centrados em ideias escravagistas, com personagens para sempre subalternizados, sem nome ou sobrenome e sem referência geoespacial-emocional-cultural, eternizados como o outro, o estranho e o estrangeiro. Para tanto, encara-se o desafio de se utilizar de um arcabouço linguístico do idioma português, que nem sempre (ou quase nunca) nos favorece, e passamos em nossos trabalhos a mesclar termos ditos eruditos e os coloquiais próprios da variedade linguística que é a nossa e que nos autorrepresenta, numa reconstrução estética da palavra, muitas vezes recorrendo aos neologismos ${ }^{10}$ e a transgressão, invertendo a imagética pejorativa existente, criando uma nova forma de nos dizer e dizer o Brasil. Cabe ainda salientar que na década de setenta se dá a inversão do isolamento dos escritores-escritores negros-negras dentro da chamada literatura brasileira, para a formação de coletivos de escritas, publicações e reflexões. Mas esse é assunto para outro artigo. Meu intuito aqui foi apenas referenciar, embora parcialmente, de onde brotam e se alimentam minhas criações literárias.

\footnotetext{
${ }^{1}$ Ver a respeito: Ana Flávia Magalhães Pinto, Imprensa negra no Brasil do século XIX. São Paulo, SP: ed. Selo Negro, 2010.

2 Joana Maria Ferreira da Silva, Centro de Cultura e Arte Negra - CECAN. São Paulo, SP: ed. Selo Negro, 2010.

${ }^{3}$ Lélia Gonzalez /Carlos Hasenbalg. Lugar de negro. Rio de Janeiro, ed. Marco Zero, 1982.

4 Ver também: Jônatas Conceição (org.). 1978-1988: 10 anos de luta contra o racismo - Movimento Negro Unificado. São Paulo: Confraria do Livro, 1988.

${ }^{5}$ FECONEZU: Manifestação cultural negra que acontece uma vez por ano, no mês de novembro, em uma cidade do interior paulista, que no ano 2020 realizará sua 42a edição.

${ }^{6}$ Aline Costa, "Uma história que está apenas começando", in Cadernos negros três décadas: ensaios, poemas, contos. Orgs. Esmeralda Ribeiro; Marcio Barbosa. São Paulo: Quilombhoje Literatura: Secretaria Especial de Promoção da Igualdade Racial, 2008.
} 
${ }^{7}$ Ibidem.

${ }^{8}$ Ver a respeito: Literatura Quilombhoje (org.) vários autores. Reflexões sobre a literatura afro-brasileira. São Paulo: Conselho de participação e desenvolvimento da comunidade negra, 1985.

${ }^{9}$ Arnaldo Xavier; Cuti (Luiz Silava); Miriam Alves. Criação crioula, nu elefante branco. São Paulo: Imesp, Imprensa oficial do Estado de São Paulo, 1987.

${ }^{10}$ Um dos exemplos emblemático do uso desse recurso: Jamu Minka. Teclas de Ébano. São Paulo, Ed. do Autor, (dentro do projeto do Quilombhoje Literatura de publicação individual dos autores que faziam parte do coletivo), 1986 (poema) 


\section{Balada no Balanço}

Sonhava com mar

Sentava-se no balanço a balançar

Mirava o azul infinito

Todo um céu para flutuar

Deixar-se levar

Assim vivenciou o Olo(depois)

Conheceu o kúm(mar)

Vivenciou as profundezas de Olokum

No balanço a balançar

Por entre as árvores conheceu o fundo do mar

Infinda se foi de mãos dadas a si mesma 


\section{Brado}

Que ninguém

Ninguém mesmo

Se interponha

Aos meus óleos

Essenciais

A minha pele brilho-perfume

Em noite de lua nova

Que ninguém

Ninguém mesmo

Se atreva a pôr a mão

Nos meus tons

Cores carmim, violeta, rubro-negro

Havia esquecido como era bom

Batom colorindo os lábios

Não mais ressequidos

Que ninguém

Ninguém mesmo

Se interponha entre eu

E eu mesma, eu e mim

O meu ser

O meu não ser

Que ninguém

Ninguém mesmo!

Interrompa os meus silêncios 
REDE INTERNACIONAL LYRACOMPOETICS

"Mudando a história com palavras e persistência" (depoimento e poemas)

\section{Breve}

As palavras me agasalham

Aquece

Enxugam minhas lágrimas

No lenço de papel

Os poemas ficam registrados 


\title{
Fora e Dentro
}

\author{
Corpos e não corpos \\ Flutuam \\ Ligam \\ partículas que movimentam vontades \\ Eternizam \\ o etéreo que há em mim \\ Expando \\ alço lugares \\ vou \\ fundo e fundo \\ perco-me \\ acho-me \\ abraçada a mim \\ por entre as fendas profundas \\ no marvida
}

NOTA

* Miriam Alves é Bacharel em Serviço Social, integrante do Quilombhoje Literatura de 1980 a 1989 . Trinta e sete anos de carreira, poemas e contos publicados em Cadernos Negros a partir do volume cinco (1982). Autora dos livros: Momentos de Busca (poema, 1983); Estrelas nos Dedos (poemas, 1985); Brasilafro autorrevelado (reflexões, 2010); Mulher Mat(r)iz (prosas, 2011); Bará na trilha do vento (romance, 2015); Maréia (romance, 2019). Escritora visitante, ministrou cursos na Universidade do Novo México e na Escola de Português de Middlebury College, nos Estados Unidos da América. Co-organizou duas antologias bilingues Portuguêsınglês: Finally Us: Contemporary Black Brazilian Women Writers (1995); Women Righting - Afro-Brazilian Women's Short Fiction (2005). 